\title{
Evidências, experiências e endemias: fatos científicos nas políticas de combate à hanseníase
}

Evidence, experiences and endemic diseases: scientific facts in policies for combatting leprosy

\section{Claudia Fonseca}

\section{(2) OpenEdition}

\section{Journals}

\section{Edição electrónica}

URL: http://journals.openedition.org/aa/5871

DOI: $10.4000 /$ aa. 5871

ISSN: 2357-738X

\section{Editora}

Programa de Pós-Graduação em Antropologia Social (UnB)

Edição impressa

Paginação: 164-187

ISSN: 0102-4302

\section{Refêrencia eletrónica}

Claudia Fonseca, «Evidências, experiências e endemias: fatos científicos nas políticas de combate à hanseníase», Anuário Antropológico [Online], v. 45 n.2 | 2020, posto online no dia 27 maio 2020, consultado o 28 abril 2021. URL: http://journals.openedition.org/aa/5871 ; DOI: https://doi.org/ 10.4000/aa.5871

\section{(c) (†) $\odot$}

Anuário Antropológico is licensed under a Creative Commons Atribuição-Uso Não-Comercial-Proibição de realização de Obras Derivadas 4.0 International. 


\title{
Evidências, experiências e endemias: fatos científicos nas políticas de combate à hanseniases
}

\author{
Evidence, experiences and endemic diseases: scientific facts in policies \\ for combatting leprosy \\ DOI: https://doi.org/10.4000/aa.5871
}

\section{Claudia Fonseca • Universidade Federal do Rio Grande do Sul - Brasil}

Professora do Programa de Pós-Graduação em Antropologia Social da Universidade Federal do Rio Grande do Sul (Brasil). Seus interesses de pesquisa incluem parentesco, gênero, antropologia do Direito e Estudos de Ciência e Tecnologia. Desde 2012, tem desenvolvido pesquisas entre afetados de hanseníase no Brasil.

Neste artigo, vendo nosso universo como um espaço político atravessado por diversas verdades morais e científicas, nos guiamos pela pergunta: como se determina a evidência científica que define a versão última da política de combate à hanseníase no Brasil e no mundo? Inspirados pelos estudos de ciência e tecnologia, assim como pela antropologia de políticas sociais, nossos interesses convergem numa antropologia de infraestrutura. Examinamos os efeitos provocados pelos diversos atores humanos e não humanos, focando primeiro na "doença em andamento" (envolvendo corpos, bacilos e nomenclaturas médicas), passando às estatísticas e metas das campanhas internacionais para "eliminar" a hanseníase (incluindo protocolos, medicamentos e estatísticas da saúde global), para desembocar na contenda cercando uma proposta de mudança no regime de tratamento (disputada por experts locais, nacionais e internacionais). Na disputa atual, vemos como, através de alianças políticas que se estendem de um lado a outro do globo, a ecologia de saberes especializados se mexe, provocando uma redefinição inesperada na hierarquia de evidências autorizadas..

Antropologia da ciência e tecnologia. Políticas públicas. Hanseníase. Infraestrutura. Medicina baseada em evidências.
In this article, conceiving our universe as a political arena including different moral and scientific truths, we are guided by the question: what processes lead up to the scientific evidence that defines public policy for combatting leprosy in Brazil and across the globe? Inspired in science and technology studies as well as the anthropology of social policy, our interests converge in the anthropology of infrastructure. Examining the effects provoked by the various human and non-human actors, we focus first on the "disease in motion" (involving bodies, bacteria, and medical nomenclatures), then on statistics and goals in the international campaigns to eliminate leprosy (including protocols, medicines, and global health statistics), arriving finally at the present-day conflict surrounding a proposed change in the treatment regime (disputed by local, national, and international experts). Here we become aware of how, influenced by political alliances extending throughout the globe, the ecology of expert knowledge is reconfigured, provoking an unexpected redefinition in the authorized hierarchy of evidence.

Science and technology studies. Anthropology of policy. Infrastructure. Leprosy. Evidence-based medicine. 
No início de 2018, apesar de passar praticamente despercebido na imprensa brasileira, se desenrolava um debate acalorado entre profissionais de saúde lidando com a hanseníase - doença contagiosa que infecta mais de 25.000 brasileiros por ano. O estopim do debate foi a proposta de um novo regime de tratamento "unificado" que, em vez de variar conforme o grau de severidade da doença, seria igual para todos os novos pacientes. A inovação representava um cocktail de poliquimioterapia mais forte para casos leves, enquanto reduzia pela metade, de doze para seis meses, a duração do tratamento para casos mais graves. Argumentos a favor da mudança e contra ela materializaram-se no comitê técnico assessor nomeado pelo Ministério da Saúde, bem como em diversos manifestos emitidos por associações profissionais e fóruns relevantes de mídia social.

A contenda sobre a mudança de protocolo foi o estopim de nossa investigação. Queríamos entender o surgimento de tamanho conflito no seio de uma comunidade de cientistas, administradores, médicos, trabalhadores de saúde e pacientes que, até recentemente, pareciam trabalhar unidos para combater o inimigo comum: a hanseníase. Investigações preliminares nos convenceram que não cabia qualquer explicação precipitada - sobre, por exemplo, os interesses de companhias farmacêuticas num novo protocolo. (O remédio, doado pela companhia farmacêutica suíça, Novartis ${ }^{1}$, é distribuído gratuitamente pela OMS conforme as necessidades de cada país). Tampouco encontramos uma diferença nas credenciais profissionais ou engajamento militante de pessoas de um lado ou de outro. Tanto aqueles a favor como aqueles contra a mudança de regime expressavam firme convicção quanto à validade dos fatos científicos que justificavam seu posicionamento. Foi justamente porque não se prestava a nenhuma explicação fácil que essa controvérsia nos apresentava o desafio instigante de entender, conforme a abordagem ator-rede (Latour, 2005), as dinâmicas em jogo na assembleia de elementos heterogêneos - com atenção especial às tecnologias infraestruturais (Bowker; Star, 1999) - que compõem uma política de combate a uma doença infecciosa ainda endêmica em vários países. Vendo nosso universo como um espaço político atravessado por verdades morais e científicas diferentes, nos guiamos pela pergunta: como se determina a evidência científica que define a versão última da política de combate à hanseníase no Brasil e no mundo?

Por envolver um grande número de atores localizados em sites distintos, examinar os fios interligando os fatos científicos e as políticas de combate à hanseníase apresenta um desafio metodológico particular. Indo além da observação participante clássica, cabe um procedimento que explora as conexões e disjunções entre processos operando em escalas diversas - entre atores, instituições e discursos, entre o mundo organizacional e práticas cotidianas e em momentos históricos distintos (Shore; Wright, 1997). Seguindo esse roteiro, recorremos entre 2013 e 2019 a materiais oriundos de várias fontes. Além do trabalho etnográfico em torno de ex-colônias hospitalares em diferentes regiões do Brasil ${ }^{2}$ (ver Fonseca, 2017), fizemos contato com ativistas do movimento social MORHAN (Movimento de Reintegração das Pessoas Atingidas pela Hanseníase), participamos nas mídias sociais, entrevistamos profissionais de saúde com experiência nos centros espe-
$\S$ Gostaria de agradecer as sugestões e críticas dos dois pareceristas que me ajudaram mais do que podiam imaginar.

1 Conforme sua política de responsabilidade social, desde 2000, a companhia tem renovado a cada cinco anos seu compromisso de fornecer esses remédios gratuitamente à OMS. O último acordo fala numa doação no valor de "mais de \$40 milhões" de dólares em cinco anos (Novartis, 2015). Disponível em: https://www. novartisfoundation.org/news/ media-releases/novartis-continues-commitment-go-last-mile-effort-eliminate-leprosy. Acesso em: 20 out. 2019.

2 Agradeço à recém-doutora Glaucia Maricato, que colaborou em praticamente todas as etapas dessa pesquisa. 
cializados de hanseníase, assistimos a eventos científicos e audiências públicas, consultamos revistas médicas especializadas e estatísticas, e analisamos planos globais e orientações oficiais, disponíveis na internet, de órgãos nacionais e internacionais de saúde.

Para organizar esse material, iniciamos - depois de um breve esclarecimento sobre nossas inspirações teórico-metodológicas - com uma consideração dos elementos microscópicos da rede sociotécnica relevante, fitando a "agência" da Mycobacterium leprae em interação com tecnologias médicas e corpos específicos. Vemos como o bacilo produz materialidades que se esquivam das categorias binárias de classificação (como, por exemplo, doente/curado), apresentando desafios particulares às infraestruturas da saúde global normalmente empregadas para contar, controlar e tratar as doenças contagiosas. Saltando para outra escala, focalizamos então a contagem de "novos casos" da doença pela Organização Mundial de Saúde (OMS), procurando entender a produção e os efeitos de categorias classificatórias para quadros numéricos da saúde global. Ao ver como o mapeamento estatístico se articula com protocolos de tratamento, além das agendas políticas de administradores nacionais, fica mais claro como a implementação dessa política de saúde é forjada num espaço de disputa e negociação.

Na última parte de nossa discussão, trazendo detalhes sobre o conflito envolvendo a proposta em 2018 de um novo protocolo de tratamento, chegamos ao cerne de nossas preocupações: a disputa sobre quais verdades científicas são chamadas a prevalecer nas políticas de combate à hanseníase. Rastreamos os componentes principais desse conflito, desde a proposta inicial lançada por um grupo consultivo da OMS até a reação dos profissionais de saúde locais, com atenção especial à maneira como as perspectivas são moldadas, justificadas e rejeitadas pela mediação de estatísticas e evidências científicas. Tocando inevitavelmente nos debates sobre ECRs (ensaios controlados randomizados) - o famoso "padrão ouro" da medicina baseada em evidencias -, acionamos a noção de "ecologia de evidências" (Briggs, 2016) para explorar os pesos diferenciais atribuídos às diferentes formas de conhecimento. Sugerimos, por fim, que, através de mobilização ativista e alianças políticas que se estendem através do globo, a ecologia de saberes especializados mexe, provocando uma redefinição inesperada na hierarquia de evidências autorizadas.

\section{A infraestrutura dos fatos científicos}

Nossa investigação é pautada nas reflexões de Ludwik Fleck (2005) que, já nos anos 1930, abriu caminho para pensar o fato científico como "um evento na história do pensamento", produto e produtor de uma comunidade de pessoas que trocam ideias ou que interagem intelectualmente. Conforme esse autor, a validação de uma alegação científica depende em grande medida desse tipo de "coletivo de pensamento" e sua eficácia em conferir robustez aos fatos através do compartilhamento concertado de certa infraestrutura tecnológica (métodos, terminologias, instrumentos) e práticas. "A solidariedade intelectual entre iguais a serviço de uma mesma ideia" agiria para conferir solidez a determinadas configurações intelectu- 
ais - independentemente de seu conteúdo ou de seus fundamentos lógicos. Nessa teoria comparativa do conhecimento, a versão dominante dos fatos, consagrada pelo senso comum, não é necessariamente a única possibilidade lógica. Porém, é aquela tributária de um coletivo de extensão temporal e/ou espacial ampla que, conforme suas conexões do momento, constitui a aparência de certeza.

Essas ponderações nos mergulham no tema já clássico na área de estudos de ciência e tecnologia: a relação entre ciência e poder. Conforme Latour, "a ciência é a política exercida por outros meios" (1983, p. 150). Aproveitando essa provocação, exploramos neste artigo um elemento relevante a ambos os domínios: a importância da escala na produção de versões diferentes de verdade (Carr; Lempert, 2016). Como observado por Latour (2000, p. 293-294), os "fatos críveis e artefatos eficientes" da ciência ganham força com o aumento do número de elementos amarrados à alegação, isto é, com a quantidade de pessoas recrutadas, a abrangência dos instrumentos empregados e a extensão das instituições participando da definição e do registro de dados. Trata-se de uma maneira particular de estabilizar fatos da realidade que se acelera desde o século XVIII, acompanhada pela importância crescente da estatística não só na produção da ciência, mas também no funcionamento do governo. A lógica dos "grandes números", materializada em tabelas de dados quantitativos, passa a abranger uma diversidade cada vez maior de esferas da vida "natural" e "social", aparentemente domando incertezas e facilitando o planejamento e a implementação de políticas estatais (Hacking, 1990). Nessas novas tecnologias de "governo a distância", a realidade é objetivada - certa versão das coisas e acontecimentos ganha validade - através de uma série de categorias e registros numéricos. $\mathrm{E}$, como apontado por $\mathrm{A}$. Desrosières (1993, p. 12), quanto mais amplo o investimento na definição das categorias convencionadas de equivalência que subjazem esses registros, maior a realidade do produto.

Aproveitamos os aportes teórico-metodológicos também das análises centradas em políticas públicas, lideradas por Shore e Wright (1997). Desses autores, trazemos um caveat inicial: é preciso se precaver das visões prescritivas e normativas, comuns em estudos dessa área, que concebem as políticas sociais em termos da imagem pacata de uma racionalidade administrativa linear. Pelo contrário, essas políticas devem ser lidas "como textos culturais, como instrumentos classificatórios com significados diversos, como narrativas que servem para justificar ou condensar o presente, ou como instrumentos retóricos e formações discursivas que têm como função empoderar algumas pessoas e silenciar outras" (1997, p. 6) Os autores observam que a dimensão eminentemente política dos programas sociais é, costumeiramente, mascarada por uma linguagem técnica que obscurece as decisões morais tomadas para produzi-los. Para fazer jus à complexidade do fenômeno, a análise de qualquer política social começaria pelo estranhamento do sistema classificatório usado para descrever, difundir e implementá-la. $\mathrm{O}$ exame detalhado da interconexão entre categorias e instituições operando em escalas diferentes seria dirigido à detecção do entrecruzamento de múltiplas e conflitantes estruturas de poder. 
Alimentados, por um lado, pelos estudos de ciência e tecnologia, e, por outro, pela antropologia de políticas sociais, nossos interesses convergem na proposta de Bowker e Star (1999) para uma antropologia de infraestrutura. Reconhecendo na "arqueologia prática" de Foucault uma inspiração importante, os autores focam suas energias nas classificações acionadas numa variedade de atos da vida mundana: estabelecer uma certidão de óbito, diagnosticar uma doença, avaliar o desempenho profissional de um profissional de saúde... Ao propor uma "pragmática" da tecnologia informacional atual, concebem as categorias e padrões convencionados das infraestruturas como uma forma de trabalho, com suas respectivas dimensões política, técnica e moral (1999, p. 5), suscitando as perguntas: que trabalho é realizado pelas categorias convencionadas? Quais as pessoas ou entidades que fazem esse trabalho? O que acontece com os casos que não cabem facilmente dentro do esquema?

A força de uma infraestrutura - definida pelos autores como ordem negociada de práticas, tecnologias e recursos - derivaria em grande medida do fato de ser virtualmente invisível e raramente questionada. Nessa moldura, possíveis atritos provocados pela articulação de visões éticas, políticas e epistemológicas muito distintas são facilmente ofuscados pelos mecanismos aparentemente neutros de coleta, classificação e organização da informação. Para realimentar a possibilidade de debate e contestação, Bowker e Star recomendam seguir uma pauta investigativa que tira da sombra e coloca em destaque as condições de produção e efeitos da infraestrutura. Esse tipo de "inversão infraestrutural" levaria ao reconhecimento, por um lado, da complexidade das interdependências de redes e padrões técnicos, e, por outro, do trabalho convergente da política e da produção de conhecimentos. Daria ênfase aos "fios minúsculos normalmente invisíveis, lhes atribuindo a proeminência causal que [em outras perspectivas analíticas seria] atribuída a atores heroicos, movimentos sociais ou costumes culturais" (1999, p. 34).

Cabe insistir nesse método que procura levantar detalhes e conexões relevantes que são costumeiramente negligenciados (Fleck, 2005, p. 47). Voltando à frase de Latour citada acima, devemos lembrar que o autor caracteriza os "outros meios" (acionados pela ciência) como "fontes novas e imprevisíveis de deslocamentos - poderosas [justamente] por serem ambíguas e imprevisíveis" (Latour, 1983, p. 168). Os leitores familiarizados com a linguagem da teoria ator-rede, reconhecerão nessas fontes os "mediadores" da rede sociotécnica que "transformam, traduzem, distorcem e modificam o significado dos elementos que transmitem" (2005, p. 39). Sugerimos que, no nosso estudo - das políticas de combate à hanseníase -, à medida que nossa análise ganha materialidade, adentrando as operações efetivadas pelos diversos atores humanos e não humanos (bacilos, medicações, infraestruturas burocráticas, nomenclaturas médicas, autoridades nacionais, experts internacionais, profissionais de saúde, entre outros), os acontecimentos driblam nossas expectativas. Certamente, a nossa pesquisa não é a primeira a trazer os aportes da ciência e tecnologia para ressaltar as ambiguidades poderosas nas redes acionadas para o combate de uma doença contagiosa ${ }^{3}$. Contudo, sugerimos que o caso de hanseníase traz algumas particularidades não detalhadas em outro
3 Ver, em particular, estudos sobre doenças sexualmente transmitidas: Fleck, 2005; Carrara, 1996; Fassin, 2007; Duarte, 2016. 
lugar, contribuindo eventualmente para debates tanto entre adeptos da análise crítica como entre ativistas e profissionais voltados para políticas de intervenção.

\section{2. "A doença em andamento": um encontro singular entre bacilos e corpos}

Bowker e Star (1999), focando no exemplo da tuberculose nas suas diversas metamorfoses ao longo do século XX, fazem uma clara demonstração de como a doença se esquiva da nosologia médica. Ao narrar a interação entre biografias, corpos, curas e pessoas, procuram sublinhar o caráter irredutivelmente local das experiências individuais em contraste ao caráter inevitavelmente padronizado dos protocolos médicos. Em muitos aspectos, a hanseníase se mostra como exemplo igualmente revelador de uma "doença em andamento", cuja realidade é forjada no entrecruzamento de corpos, bacilos, classificações burocráticas, e a experiência dos próprios pacientes.

Para desenvolver essa proposição, tomamos como ponto de partida um momento da pesquisa de campo que realizamos em 2017 em um centro de internamento para pacientes de hanseníase na periferia de São Luis de Maranhão. Lá, sentado na varanda junto com dois outros pacientes do serviço, encontramos Denilson, um rapaz com 22 anos de idade, que, internado há quase dois meses, estava a ponto de iniciar seu segundo ciclo de tratamento em três anos. Dos pés até a cabeça, estava com a pele coberta de pequenas erupções inflamadas, circundadas de crostas e escamas avermelhadas, e gemia de dor. Foi a partir desse jovem interiorano, de cor e feições sugerindo uma origem afro-indígena, que passamos a contemplar quão complicada é essa doença.

Uma primeira complicação diz respeito à nomenclatura usada para descrever de quê o paciente padece. É ou não é hanseníase? Lembramos que, não obstante as concepções populares ${ }^{4}$, especialistas geralmente concordam que a hanseníase não é uma doença de diagnóstico fácil (Trindade et al., 2009; Salgado et al., 2016; Salgado et al., 2018). Apesar de ser classicamente associada a lesões conspícuas de pele, se desenvolve antes de tudo através dos caminhos relativamente invisíveis dos nervos. Os sintomas, especialmente no início da doença, são geralmente difusos - dor nas juntas, certa insensibilidade nas extremidades, eventualmente manchas na pele -podendo coincidir com um sem número de aflições diferentes. Existem exames laboratoriais para detectar a presença do bacilo Mycobacterium leprae no corpo do paciente, sendo a baciloscopia - que passa pela coleta de esfregaços do lóbulo auricular, cotovelo ou lesões - o mais comum. Porém, as contagens bacilares, especialmente nos estágios iniciais da doença, costumam dar resultados incertos (A própria OMS (WHO, 2003, p. 24) recomendou descontinuar o uso desse exame, alegando que costuma detectar menos de 15\% dos casos diagnosticados).

Um caso paradigmático das dificuldades cercando a detecção de hanseníase foi relatado na mídia gaúcha em 2018. O artigo de jornal narra a história de uma mulher cujos sintomas apareceram no final da adolescência (Stefani, 2018). Porém, ela tinha concluído a universidade e formado uma família antes
4 Ironicamente, em alguns documentos, a própria Organização Mundial da Saúde endossa a ideia de que a Hansen é uma doença sem complicações, com ferramentas "práticas e simples" para o diagnóstico (OMS: Estratégia Final Push, 2003). 
que, durante a internação hospitalar por dores agudas "misteriosas" nas articulações, finalmente recebesse o diagnóstico de hanseníase. Já que a mulher mora há tempo no Rio Grande do Sul - um estado em que a hanseníase foi oficialmente "eliminada" -, os médicos simplesmente não tinham considerado antes a possibilidade desta doença.

Em todo caso, pela associação estreita entre a hanseníase e a miséria econômica (Lockwood, 2004), podemos supor que a maioria dos pacientes brasileiros terá de depender dos recursos precários do SUS. Sem possuir recursos para a realização de exames adequados, os pequenos postos de saúde localizados nas regiões interioranas mais afetadas têm poucos instrumentos para determinar um diagnóstico. Entende-se, então, que o bacilo pode se instalar no corpo da pessoa e progredir durante anos sem ser detectado. No caso de Denilson, por exemplo, é provável que, antes de fazer a primeira rodada de poliquimioterapia (PQT), o paciente já tivesse passado por uma série de consultas frustrantes com médicos de seu município, sem diagnóstico certo. E, tal como acontece com muitos outros, a doença já estava numa fase relativamente avançada antes do paciente ser encaminhado enfim ao Centro especializado para tratamento.

A segunda complicação vem na hora de classificar a doença em grau de severidade - multibacilar ou paucibacilar - distinção importante já que determina o regime de tratamento, tanto o conteúdo do cocktail medicamentoso quanto a duração do tratamento (seis ou doze meses). Em muitos - talvez a maioria de casos, existem dúvidas quanto à categoria da condição do paciente. Os próprios critérios de classificação recomendados pela OMS têm variado ao longo das últimas décadas, com ênfase ora no número de lesões na pele, ora na contagem de bacilos encontrados no exame laboratorial, ora na constatação de determinados sintomas clínicos (ver Malathi; Thappa, 2013; Maricato, 2019). Contudo, a condição de Denilson, mesmo na primeira vez que chegou ao centro de referência, não deixava margem de dúvida quanto à gravidade de seu caso. A partir daquele momento, passou a constar nos registros como caso ativo de hanseníase multibacilar. Assim, teria que percorrer uma vez por mês os $250 \mathrm{~km}$ de estrada que levava de seu vilarejo até a capital, pois, seguindo protocolo, tinha que tomar a dose reforçada mensal do cocktail na presença da supervisora médica. Só assim receberia a plaqueta contendo as pílulas para os demais dias do mês. Depois de um ano desse vaivém, isto é, doze viagens, Denilson seria automaticamente reclassificado na categoria "alta por cura".

Agora chegamos na terceira complicação - a definição ambígua de "cura". Finalizando o tratamento, em vez de voltar ao normal, Denilson piorou. O jovem nos disse que, "de primeiro, achava que era por causa que pegava muito sol na lavoura”. Porém, aos poucos foi desconfiando que a doença não tinha sido tão "curada" assim. Fazia mais de um ano desde o fim de seu tratamento quando finalmente chegou de volta ao centro hospitalar da capital. Os profissionais inicialmente eliminaram a possibilidade de falência de tratamento ${ }^{5}$ ou de recidiva (aliás, conforme orientações do Ministério da Saúde, via de regra "recidivas" só ocorrem mais de cinco anos depois do fim do tratamento ${ }^{6}$.) Assim, a condição de
5 Condição que ocorre quando mesmo após o fim da medicação, o paciente ainda apresenta carga alta de bacilos vivos.

6 Portaria $\mathrm{n}^{\circ} 3.125$, de 7 de outubro de 2010 . 
Denilson foi classificada como "episódio reacional”: isto é, apesar do tratamento padrão ter matado e fragmentado toda a bactéria, seu sistema imunológico continuava a atacar os focos desativados do bacilo, provocando danos a tecidos sadios.

Especialistas são praticamente unânimes em reconhecer que boa parte das sequelas provocadas pela hanseníase ocorre por causa dessas reações autoimunes. Em outras palavras, a doença pode continuar provocando sérios danos aos pacientes mesmo anos depois de eles serem classificados como "curados" (Cruz, 2016; Fonseca, 2017; Maricato, 2019). Não é nada estranho, portanto, que os pacientes nem sempre tenham clareza quanto ao estado de sua saúde - se já foram curados ou se continuam doentes. E não é incomum ouvir de nossos interlocutores - em particular, daqueles que sofrem de sequelas - que, não obstante os slogans repetidos durante as campanhas de saúde, não acreditam que essa doença tenha cura. No caso de Denilson, nem os profissionais do Centro conseguiram definir com certeza em qual categoria sua condição cabia. Depois de dois meses de tratamento com fortíssimos corticoides anti-inflamatórios sem surtir efeito, passaram a contemplar a possibilidade de que talvez não fosse episódio reacional. Tateando o caminho por um procedimento de tentativa e erro, pendiam agora para o diagnóstico de recidiva, isto é, de hanseníase ativa, para a qual cabia uma nova rodada de PQT.

Inicialmente, o pessoal médico do Centro maranhense nos disse que todos os quinze pacientes internados na ala hospitalar estavam lá por causa de "reações"7. Porém, aos poucos, lembraram como vários desses pacientes acabaram fazendo uma nova rodada de PQT - o que significa, essencialmente, recidiva. Seu Flávio, já com 74 anos de idade, seria um bom exemplo. Tinha sido internado no hospital-colônia ainda adolescente, quase sessenta anos atrás. Só depois da chegada do cocktail PQT em 1981, conseguiu se “curar", mas nas décadas subsequentes acabou se submetendo a mais duas rodadas do tratamento. No caso dele, a enfermeira nos confia, houve suspeita de reinfecção e não simplesmente de recaída. O ponto aqui é que, nem no centro especializado, existe método seguro para distinguir entre a recidiva (doença mal curada), a reação (problema autoimune) e a reinfecção (o paciente curado exposto a novos focos de transmissão), pois todas essas condições (apelidadas por uma observadora médica como "as rés" da doença) produzem sintomas muito semelhantes.

Em suma, não obstante as narrativas otimistas nas campanhas contra a hanseníase, a doença continua em muitos aspectos um mistério. Tem afinidades com outras doenças (o bacilo de tuberculose, por exemplo), mas suas particularidades dificultam o desenvolvimento de claros indicadores de diagnóstico e cura, quem dirá de vacinas preventivas. O bacilo, identificado há mais de cem anos, nunca chegou a ser cultivado em proveta (nos laboratórios, sua viabilidade é testada nas patas de camundongos). E, tendo tempo de incubação incerta (chegando a demorar anos antes de se manifestar no corpo do doente), pode ser difícil rastrear os "vetores” de transmissão. Glaucia Maricato (2019), investigando o assunto sob a lupa dos estudos de ciência e tecnologia, mostra como continuam (e reemergem) questões básicas nos debates científicos: se a doença é da alçada de especialistas
7 No seu estudo de um centro de referência na cidade de Rio de Janeiro, Cruz (2016) também chama atenção para a grande proporção de pacientes que vieram para atendimento por causa de episódios reacionais. 
de dermatologia, neurologia ou do sistema imunológico; se é transmitida apenas de pessoa a pessoa ou se existem outros vetores (animais, água, etc.). Outro problema é que o bacilo, uma vez instalado no corpo humano, não segue uma trajetória predefinida, se desdobrando em formas muito variadas de doença conforme a interação com o corpo hospedeiro. Como diz Alice Cruz (2016), trata-se de uma doença cuja fenomenologia não se encaixa facilmente nas narrativas da medicina heroica calcada na ideologia da cura. A questão se coloca, então: como ajustar essa doença esquiva e constantemente "em andamento" às classificações protocolares da saúde global?

\section{A contagem de casos: um encontro entre números, tratamentos e metas}

Não há dúvida de que o declínio mundial da doença, observado já em meados do século XX, foi dramaticamente acelerado por uma terapia medicamentosa - a poliquimioterapia (PQT) - consolidada em 1981. Num esforço articulado entre especialistas da OMS, as várias secretarias nacionais de saúde e as organizações filantrópicas que financiavam o custo (Fundação Nippon e a Fundação Novartis para o Desenvolvimento Sustentável), a medicação se tornou gradativamente acessível a pacientes do mundo inteiro. Em 1991, a OMS anunciou a meta de "eliminar" a hanseníase como um problema de saúde global até o ano 2000, isto é, reduzir a média de casos a menos de 1 paciente por 10.000 pessoas. E dez anos depois, exibiu estatísticas demonstrando que tinha efetivamente alcançado seu objetivo.

A hanseníase tinha sido eliminada "em nível global", restando apenas cinco ou seis países onde o número de casos ultrapassava a meta estipulada. Desde 2006, o Brasil é considerado o único país do mundo a não ter eliminado a doença e, em número total de casos, o país perde apenas para a Índia.

Sem negar os avanços globais, nem a gravidade da endemia no Brasil, sugerimos que cabe olhar de mais perto como essa narrativa estatística emerge através de infraestruturas negociadas entre categorias, tratamentos, e registros realizados em determinadas circunstâncias políticas. Em primeiro lugar, cabe notar como o regime de tratamento tem um impacto direto sobre as estatísticas - não só por causa de um eventual aumento de curas, mas também pelo encolhimento temporal do critério de contagem. Explico. Os dados da OMS sobre a hanseníase são baseados na "taxa de prevalência". Representando o número de pessoas que estão fazendo o tratamento padrão em um dia determinado (digamos, 31 de dezembro), essa taxa está intimamente vinculada ao protocolo médico do momento. Nos dias pré-PQT, quando o tratamento podia durar cinco anos ou mais, os pacientes se acumulavam nos registros de um ano para o outro. Com o surgimento de dois novos antibióticos em 1981, a duração recomendada do tratamento baixou. Para os casos leves - paucibacilares (PB) - foi definido um regime de dois antibióticos durante 6 meses - fórmula que continua até hoje. Para os casos mais avançados -multibacilares (MB), o cocktail de três antibióticos era para durar 24 meses ou até o nível dos bacilos do paciente (detectado pela baciloscopia) cair para zero. Em 1994, o tratamento padrão para hanseníase MB foi limitado a 24 meses, passando 
em 1998 a 12 meses. Não é, portanto, nada surpreendente que as estatísticas globais mostrem um declínio acentuado de casos entre 1994 e 1996 e, novamente, entre 1998 e 2000. Dada a maneira particular como as taxas são computadas, era previsível que os cortes sucessivos na duração de tratamento trariam repercussões nesse sentido (Talhari et al., 2012).

Em segundo lugar, cabe olhar para a dinâmica desencadeada pela OMS com seu uso estratégico de dados comparativos de desempenho nacional. Em anos recentes, diversos antropólogos têm observado como a tecnologia de rankings, apoiada numa infraestrutura estatística difundida em escala global, funciona hoje como um mecanismo de disciplina transnacional (Gupta, 2012; Bruno; Didier, 2013; Merry, 2011; Shore; Wright, 2015). A publicidade dada à classificação de performances nacionais envolve os países em uma "colaboração competitiva" que permite avançar certas metas pela incitação à autovigilância, sem recorrer a medidas repressivas. A ironia é que essa tecnologia (que Gupta, no caso indiano, descreve como "sumamente reducionista") pode levar a valorizar a exibição de números apropriados por cima de ganhos substantivos na qualidade de vida das pessoas. Trazendo essas reflexões para nosso caso, somos levados a perguntar se a fixação nas estatísticas, atestando assim a "eliminação" da hanseníase em determinado território, não estaria tentando autoridades nacionais a manipular seus registros. Mais do que conter os estragos da doença, sua preocupação seria afastar de suas fronteiras o estigma da doença, ostentando a prova numérica de que o país está seguindo à risca a agenda da OMS.

Consideremos o caso da Índia. De 2005 a 2006, a taxa nacional de prevalência caiu quase $75 \%$, permitindo ao país anunciar que tinha finalmente "eliminado" a hanseníase. Céticos, porém, logo passaram a perguntar se administradores não haviam introduzido ajustes não previstos no sistema nacional de registro. Acatando as orientações das novas campanhas da OMS, as autoridades indianas tinham retirado do rol todos os pacientes "curados" (i.e., aqueles tendo completado o tratamento padrão). No entanto, indo mais longe, também tinham eliminado uma série de outros casos: pacientes com lesões únicas, os "abandonos" (que tinham desistido no meio do tratamento) e os pacientes recidivas (para os quais cabia uma segunda rodada de tratamento). Acusava-se as equipes locais de saúde de terem desistido dos programas de "busca ativa", limitando o registro de novos casos à "relatoria voluntária". Além do mais, em algumas regiões do país, fiscais tinham exigido que o diagnóstico fosse validado por um leprólogo certificado, antes que o caso pudesse ser incluído no rol oficial de estatísticas (Talhari et al., 2012). Uma pesquisa de amostra encomendada pelo governo indiano em 2010, destoando das estatísticas oficiais, mostra a persistências de taxas altas de hanseníase no país. Porém, essa pesquisa não parece ter suscitado grande interesse. Tampouco alterou o status da Índia no ranking na OMS, no qual segue classificada entre os países que "eliminaram" a doença (Lockwood et al., 2014).

No Brasil também, a trajetória dos dados mostra idiossincrasias. Em torno do ano 2000 houve um aumento atípico da taxa de prevalência - aumento que os analistas geralmente atribuem a um corpo dedicado de especialistas e agentes 
comunitários de saúde que envidaram esforços para a identificação e o tratamento de pacientes. Em compensação, os números de 2004 mostraram uma queda importante na deteç̧ão de novos casos, levando funcionários do governo a anunciar que, finalmente, o país havia eliminado a hanseníase. Foi só em meados de 2005 que, reconhecendo que os registros de outubro a dezembro 2004 haviam sido inadvertidamente extraviados, as autoridades foram obrigadas a voltar atrás, retratando seu anúncio prematuro de "eliminação" (Lockwood et al., 2014). Mais uma vez em 2016, autoridades brasileiras estavam transmitindo a aliados no cenário internacional o recado de que o país havia finalmente eliminado a hanseníase ${ }^{8}$. $\mathrm{E}$, novamente, uma vez analisados com maior cuidado, os dados confirmaram que o Brasil ainda não tinha alcançado a meta desejada.

Dado esse histórico de variações estatísticas abruptas, não é surpreendente que profissionais e pesquisadores do campo de saúde em diversas partes do mundo demonstrem certo ceticismo em relação a números oficiais. Médicos e pesquisadores brasileiros expressam suas dúvidas em publicações com títulos reveladores: "Are leprosy case numbers reliable?" (Salgado et al., 2018) e "What do we actually know about leprosy worldwide" (Salgado et al., 2016) ${ }^{9}$. No Brasil, citando evidência da persistente subdetecção, especula-se que a prevalência de hanseníase seria de três a cinco vezes maior do que a taxa oficial ${ }^{10}$. Ao mesmo tempo, analistas da situação global fazem ponderações sobre os “milhões” de casos de hanseníase silenciados nas estatísticas da OMS (Smith et al., 2015), em larga medida por causa da fixação na ideia de eliminação.

Essa fixação nos leva à terceira consideração sobre a infraestrutura informacional coordenada pela OMS: os efeitos do carro-chefe das campanhas - a retórica de eliminação - para o campo de intervenção como um todo. Especialistas da OMS empregavam esse termo já nos anos 1990, malgrado críticas de que a meta numérica, abaixo da qual o perigo de uma recrudescência da doença era supostamente eliminado, carecia de qualquer justificação científica (Lockwood et al., 2014). As tensões em torno do termo tinham revelado dois blocos: por um lado, os experts da OMS em colaboração com representantes da Fundações Nippon e Novartis; por outro, os especialistas concentrados no ILEP ${ }^{11}$, uma federação de ONGs ativa desde 1966 no combate à hanseníase. Conforme estes, as campanhas de eliminação pecavam pela confiança demasiada na ideia biomédica de "cura". Acusavam a OMS de promover uma abordagem centrada na quimioterapia "quase à exclusão de outras atividades relacionadas à hanseníase, como reabilitação" (Braber, 2004; Ji, 2005). Privilegiar a ideia de eliminação arriscava deixar em segundo plano as necessidades de "centenas de milhares de 'ex-pacientes' vivendo com as consequências da doença - danos neurológicos, deformidades e outras deficiências" (Braber, 2004, p. 209). Tanto quanto a cura, gestores deviam se preocupar com a detecção precoce da doença - para prevenir sequelas debilitantes - e no acompanhamento "pós-cura" de pacientes. Para tanto, era fundamental transmitir o recado aos vários gestores nacionais de que a "lepra", longe de ser eliminada, ia continuar a ser um problema significativo durante muito tempo por vir.

Conforme esses críticos, o anúncio da OMS em 2000, de que a hanseníase ha-
8 Vide a carta de parabéns enviada em 2 de novembro de 2015 pela Fundação Nippon para a Coordenação-Geral de Hanseníase e Doenças em Eliminação, do Ministério de Saúde brasileiro.

9 Tradução para português: "Os números de casos de hanseníase são confiáveis?" e "O que sabemos realmente sobre a hanseníase em nível global?"

10 Conforme documento postado no site da Sociedade Brasileira de Hansenologia, em 20/12/2018: "Brasil quer implantar, dia 3/1, tratamento de hanseníase condenado pela OMS". Disponível em: http:// www.sbhansenologia.org.br/ noticia/brasil-quer-implantar-dia-3-1-tratamento-de-hanseniase-condenado-pela-oms. Acesso em: 19 out. 2019.

11 International Federation of Anti-leprosy Associations (Federação Internacional das Associações contra Hanseníase) 
via sido eliminada como um problema de saúde global, teria provocando o efeito oposto ao desejado - isto é, teria resultado no relaxamento prematuro dos esforços necessários para combater a doença até mesmo em regiões de persistente endemia. Administradores públicos estavam diminuindo investimentos na formação de agentes comunitários, peça central no diagnóstico precoce. A pesquisa acadêmica, assim como o interesse de estudantes em se especializar na doença, também parecia cada vez menor (Lockwood; Suneetha, 2005; Lockwood et al., 2014). E as ONGs se queixavam de que as doações financeiras, fundamentais para a realização de seus programas de intervenção, estavam minguando. As consequências da insistência retórica na ideia de eliminação eram preocupantes, especialmente diante de uma realidade em que, não obstante a diminuição generalizada de taxas de prevalência, a detecção de novos casos parecia continuar essencialmente igual e, em alguns lugares, aumentava (Talhari et al., 2012). Como resultado dessas críticas, o plano da OMS de 2006-2010 para combater a hanseníase atenuou a retórica de eliminação em favor de uma ênfase na prevenção e tratamento das deficiências e, em certos setores, a hanseníase começou a ser assimilada à categoria de "doença crônica estável” (Lockwood, 2005) ${ }^{12}$.

Observamos, assim, que nas políticas da OMS as convenções classificatórias são centrais - tanto para a coleta e confecção de dados comparáveis, quanto para a coordenação de campanhas nacionais. Mas, antes de desembocar numa "política prática" com consequências concretas, essas categorias passam por um trabalho de negociação em diferentes instâncias. Agora, ao voltar para a contenda sobre a mudança de protocolo evocada no início deste artigo, vemos de que maneira as dinâmicas em escalas diferentes - do comportamento bacilar até o impacto dos grandes números dos ensaios clínicos randomizados, passando pela mediação de administradores nacionais e trabalhadores locais de saúde - convergem numa disputa sobre a forma adequada de intervenção na vida das pessoas.

\section{Disputas sobre o protocolo de tratamento}

\section{a) Cronologias}

Lembremos que o atual regime de tratamento (12 meses de PQT com três antibióticos para casos MB, 6 meses de $\mathrm{PQT}$ com dois antibióticos para casos $\mathrm{PB}$ ), estabelecido em 1998, goza de uma estabilidade frágil há mais de vinte anos. A história do atual conflito começou em 2002, quando alguns membros de um Grupo Consultivo da $\mathrm{OMS}^{13}$ sublinharam o fato de que a classificação de hanseníase em duas categorias, com regimes distintos de tratamento, cria problemas operacionais. Em países com alta prevalência da endemia, como '[Índia, Brasil e Indonésia, boa parte dos trabalhadores de saúde não se sente segura em traçar a linha entre casos multi- e paucibacilar. A solução, na visão desses observadores, seria instaurar um regime "unificado" (também chamado "único" ou "uniforme") - composto do cocktail mais potente (de três antibióticos) para todos os pacientes, mas por um período de apenas 6 meses.

Houve protesto imediato de outros membros do Grupo Consultivo - protesto liderado por especialistas localizados na Índia que se esforçavam para travar
12 O debate entre críticos e defensores da retórica de eliminação continua - o que explica certa oscilação na linguagem usada nos planos nacionais e internacionais entre termos como "redução" ou "controle" da hanseníase e aqueles que se aproximam mais da ideia de eliminação: "lepra zero" e "um mundo sem hanseníase". Segundo Lockwood et al. (2014), as autoridades brasileiras pioneiros na crítica à retórica de "eliminação" - haviam novamente incorporado o termo em seu programa nacional de saúde até 2011.

13 WHO Technical Advisory Group (TAG) on Elimination of Leprosy. 
o entusiasmo de seu governo pelo tratamento unificado. Citando pesquisas que demonstravam altas taxas de recidiva mesmo após 12 meses de tratamento, um editorial da conceituada revista internacional Leprosy Review, etiquetou o regime unificado proposto pela OMS de "bonita ilusão" (wishful thinking) (Ji; Saunderson, 2003). O novo protocolo não apenas sujeitaria os pacientes com casos mais leves a um regime desnecessariamente pesado de medicação. Pior, pacientes com formas virulentas da doença receberiam um tratamento abreviado, aumentando a chance de eles desenvolverem resistência aos medicamentos, de sofrer recaídas ou - enquanto mal curados - de contagiarem outras pessoas. As reticências foram suficientes para adiar qualquer endosso institucional, mas os proponentes do novo protocolo receberam o sinal verde para ir em busca de evidências científicas que pudessem comprovar os benefícios de sua proposta. Surgiu, então, um projeto multicêntrico de ensaios clínicos randomizados (ECRs) em diferentes países onde a hanseníase ainda era endêmica.

Os primeiros resultados produzidos cinco ou seis anos depois - a partir de estudos na China e na Índia - foram considerados metodologicamente questionáveis. Em alguns casos, os ECRs receberam críticas por não recrutarem um número igual de casos nas categorias de pauci e multibacilar ou por não incluir um grupo de controle com pacientes seguindo o regime padrão de tratamento. Em outros, os pesquisadores não checaram os níveis bacteriológicos dos pacientes antes e após o tratamento. Mais importante, os críticos insistiram que, já que geralmente os casos de recidiva só se manifestam depois de muitos anos, nenhuma das pesquisas realizadas até então contemplava um período de acompanhamento suficiente para dar resultados convincentes (Rao et al., 2015; Rao, 2018).

Até 2012, a equipe brasileira da pesquisa multicêntrica estava produzindo pesquisas que corrigiam muitas falhas dos primeiros ECRs (Penna et al., 2017). Apoiada em um desenho que incluía o uso sistemático de baciloscopias, um grupo controle, um período de até sete anos para o acompanhamento dos pacientes e resultados amplamente difundidos por publicações em periódicos científicos internacionais, a nova fase de ECRs parecia tarimbar a validade do regime unificado. Em 2014, seu entusiasmo reforçado por evidências baseadas no "padrão ouro" do procedimento científico, o Grupo Consultivo da OMS reiterou seu apoio ao novo protocolo. A recomendação para a implantação universal do novo regime de tratamento foi oficializada no texto na Estratégia Global de Hanseníase 20162020 da OMS (OMS 2016).

A recomendação da OMS chegou à atenção oficial dos profissionais brasileiros de saúde apenas em dezembro de 2017 quando o Ministério da Saúde formou um Comitê Técnico Assessor (CTA ${ }^{14}$ para estudar a implantação nacional do novo protocolo. Fazia pouco mais de um ano desde o impeachment da primeira presidente do país, Dilma Roussef, e o governo federal ainda estava em considerável turbulência. Além da confusão política geral, os profissionais de saúde enfrentavam um contexto nacional de austeridade econômica que resultava no sucateamento do sistema SUS. Os esforços investidos no início dos anos 2000 para intensificar o combate à hanseníase pareciam estar minguando.
14 Comitê Técnico Assessor de Hanseníase da Secretaria de Vigilância em Saúde, do Ministério da Saúde (CTA-Hanseníase) SVS/MS) 
Assim, a convocação do Comitê Técnico, reunindo especialistas de sociedades médicas, centros de referência, pesquisadores científicos e movimentos sociais de pacientes, foi recebida como sinal otimista de que o governo estava levando a endemia de hanseníase a sério. Entre outros membros do Comitê, o coordenador brasileiro dos ensaios randomizados (presente no debate desde a reunião do Grupo Consultivo da OMS em 2002) constava como figura central. Apesar de considerável dissenso interno, o Comitê chegou à conclusão de que as evidências científicas demonstravam a eficácia do novo protocolo, levando o Ministério de Saúde, em abril de 2018, a recomendar a implantação do regime encurtado de tratamento em todo o Brasil.

Os defensores do novo protocolo voltavam sempre para os resultados claros dos ensaios clínicos, apoiados no rigor metodológico e o reconhecimento pela comunidade científica dos dados, já publicados em inúmeras revistas científicas de prestígio internacional. Reconheceram que, entre pacientes MB (i.e., casos mais avançados) tratados por apenas seis meses, houve um número maior de recidivas do que no grupo controle ( 7 recidivas entre 323 indivíduos contra um entre 290). No entanto, explicaram que essa diferença não era "estatisticamente significante". Da mesma forma, consideraram pouco importante o fato de os ensaios terem demonstrado, entre pacientes submetidos ao novo protocolo, uma taxa ligeiramente mais alta de progressão de incapacidades. Concluíram que suas pesquisas demonstravam que, sob o protocolo "unificado", a taxa de recidiva seria de no máximo 4,4\% (em dez anos) - bem abaixo do que o Grupo Consultivo da OMS tinha estipulado como aceitável (Penna et al., 2017; Penna et al., 2018).

Esses proponentes do regime unificado não negam a existência de doentes que não serão curados com o regime curto de seis meses - os pacientes que demonstram resistência a um ou mais antibióticos do tratamento padrão, por exemplo, ou aqueles com uma taxa inicial muito alta de bacilos. Além do mais, sempre há a possibilidade de persisters - isto é de bacilos que escapam ao efeito bactericida do tratamento e que se mantêm dormentes no corpo até proliferarem de novo. Mas consideram que essas exceções à regra podem ser detectadas no acompanhamento pós-cura e tratadas individualmente. $\mathrm{O}$ importante é reconhecer que as exceções são poucas e não invalidam a fórmula geral, voltada para o bem-estar da grande maioria (Malathi; Thappa, 2013).

Podemos ver, nos argumentos dos autores dos ECRs, a existência de um "coletivo de pensamento" (Fleck, 2005) bem consolidado - uma comunidade de interlocução intelectual que tem colaborado há tempo, desenvolvendo tecnologias particulares - coerentes com certo estilo de raciocínio - para a coleta de dados e a validação de hipóteses. A lógica dos ensaios se apoia numa noção de natureza universal, passível de ser revelada por instrumentos que se aplicam com igual eficácia numa grande variedade de contextos. Sendo uma tecnologia de custo considerável, não está ao alcance de qualquer um. Porém, tem alimentado uma imensa indústria de pesquisas envolvendo tanto universidades como empresas comerciais (Castro, 2018; Petryna, 2009; Adams, 2013). A tecnologia traz no seu bojo um determinado regime de verdade escorado na participação de um exército 
de especialistas. Lembrando as considerações sobre escala evocadas no início deste artigo, sugerimos que a força dos resultados não decorre simplesmente do rigor metodológico. Decorre também (e, talvez, acima de tudo) da extensão da rede sociotécnica envolvida, isto é, do número e extensão de "atores" mobilizados.

Ao lado dos dados fornecidos pelos ECRs, outras formas de evidência tendem a ser consideradas como sem representatividade ou ainda como meras informações anedóticas (Adams, 2013). Assim, não é nada surpreendente que, no conflito sob estudo, os autores dos mais recentes ECRs tenham anunciado que a "minoria" posicionada contra sua proposta não tem apresentado até o momento "nenhuma evidência (publicação científica) que pudesse contradizer os achados desses 17 artigos publicados e favoráveis à implementação do novo esquema terapêutico na [Atenção Primária à Saúde]" (Penna et al., 2018).

O desafio para os oponentes do protocolo era como fazer valer as evidências e as interpretações deles de que o novo esquema terapêutico arriscava trazer mais danos do que benefícios.

\section{b) Resistências}

Há indícios que, desde o início dos anos 2000, um bloco de ONGs (coordenadas em parte pelo ILEP) vinha fazendo um lobby contra a "sobre-simplificação" dos diagnósticos (que juntaria casos $\mathrm{PB}$ e MB num regime unificado de tratamento) e contra o encurtamento do tratamento dos casos MB de hanseníase. Tratava-se de uma espécie de "coletivo de pensamento" incipiente que incluía médicos e enfermeiras clinicando nos diversos países onde a doença continua endêmica. Alguns desses profissionais expressavam a opinião de que, caso fosse aprovado um regime curto de medicação, caberia inevitavelmente a eles, nas ONGs, lidar com os estragos causados a pacientes que caíam fora da norma estatística dos ECRs.

Quando, no início dos anos 2000, o governo indiano aventou a possibilidade de implantar o regime unificado no país, houve uma mobilização impressionante dos membros dessa comunidade. Conscientes da dimensão política das evidências científicas, profissionais indianos travaram alianças - através de publicações, reuniões e outros contatos na Ásia, na América Latina, na Europa - para levar seus conhecimentos "locais" para a arena da saúde global e, assim, lograram cortar o ímpeto da mudança proposta. O processo que se deu mais de quinze anos depois no Brasil não foi diferente. Na véspera da reunião do Comitê Técnico Assessor, a Sociedade Brasileira de Hansenologia tinha enviado uma "Carta Aberta" aos membros da reunião, elencando os motivos para rejeitar o protocolo proposto do regime curto (SBH, 2018). Já que, apesar de tudo, a nova proposta foi aprovada na reunião, o grupo opositor reiterou suas objeções, transformando a Carta em "Manifesto", com ampla circulação nas redes sociais e entre membros da imprensa, com o apoio institucional de um número impressionante de associações médicas no Brasil, na Europa e na Índia. Ao lado das Sociedades brasileiras de infectologia, de neurologia, e de clínica médica - e além de uma variedade de médicos hansenólogos de renome internacional -, salientava o apoio dos "mais de dez mil médicos" da Sociedade Indiana de Dermatologia, Venereologia e Hansenologia. 
Os argumentos apresentados contra uma mudança de protocolo eram de ordens diversas. Em primeiro lugar, persistiam dúvidas quanto ao rigor metodológico dos ECRs. Sem a realização de exames histopatológicos, sanguíneos ou moleculares, como garantir a precisão da classificação de pacientes em categorias multi- e pauci-bacilares? ${ }^{15}$ Sem nenhuma informação sobre os $25 \%$ dos pacientes que abandonaram o estudo, como realizar uma análise completa dos resultados? Além do mais, críticos questionavam a possibilidade de transpor para a hanseníase métodos desenvolvidos a partir de doenças bem diferentes - a tuberculose, por exemplo, em que a recidiva ocorre poucos meses após o término do tratamento: "[Em estudos de hanseníase...], o mínimo de 10 anos de follow-up deve ser obedecido, sob pena de os resultados não espelharem o real tamanho do problema, com consequências graves para os pacientes e para a cadeia de transmissão do bacilo na comunidade" (SBH, Carta Aberta, 2018).

Existia consternação também quanto à interpretação dos dados publicados. Críticos não estavam convencidos de que a diferença de resultados entre os pacientes tratados conforme o novo regime e os do grupo de controle pudesse ser avaliada como "insignificante". Citando estimativas endossadas pela OMS sobre a taxa provável de recidiva para pacientes tratados com o regime de doze meses (1\%), críticos insistiam que os resultados dos ensaios clínicos randomizados provaram (ao contrário do alegado pelos autores dos ensaios) que o novo regime "definitivamente não [era] superior" ao antigo (Rao et al., 2015).

De forma significativa, as dúvidas extravasaram para além do problema imediato. Desencadearam um processo retrospectivo, em que até mesmo o regime padrão começou a ser revisto. Constatou-se um grande número de teses, dissertações e estudos pontuais sugerindo que, para pacientes com casos avançados, existiam taxas de recidiva relativamente altas mesmo com um tratamento de doze meses. Embora geralmente conduzidos por pesquisadores acadêmicos com orçamentos restritos, com metodologias diversas, as conclusões desses estudos eram surpreendentemente semelhantes, levando um médico experiente a declarar:

Sobre os dados referentes às 12 doses, já me manifestei aqui, e repito, nunca vimos tantas recidivas e tanta resistência medicamentosa como agora. É claro que é difícil quantificar, mas quando diferentes profissionais que estão atuando com hanseníase Brasil afora começam a falar as mesmas coisas, e ver os mesmos casos, alguma coisa está acontecendo ${ }^{16}$.

Profissionais envolvidos na prática clínica apresentavam ainda outros argumentos. Evocando longos anos de experiência nos postos de saúde nas regiões interioranas do país, sublinhavam a precariedade dos recursos médicos da rede SUS onde a descentralização projetada em lei nunca foi levada ao cabo. Questionaram se, caso fosse implantado o novo protocolo, seria realista prever um "acompanhamento" pós-cura para detectar os pacientes necessitando de um tratamento mais longo. Lembravam de pessoas como Denilson que, frente aos sintomas de uma recaída, tendem a esperar muito tempo antes de pegar o caminho de volta a um
15 Ver Petryna (2009) para uma descrição de como o mínimo ajuste nos critérios de recrutamento de pacientes pode modificar de forma significativa os resultados de um ensaio clínico.

16 Cito trechos que apareceram na primeira metade de 2018 de um grupo de debate WhatsApp frequentado por mais de 200 profissionais clínicos - médicos, enfermeiras, fisioterapeutas e trabalhadores sociais trabalhando com pacientes de hanseníase em praticamente todos os estados brasileiros. Não nomeio o grupo para resguardar o anonimato dos enunciantes. 
centro hospitalar adequado. No longo intervalo, podem ter experimentado pioras devastadoras, além de desenvolver novos focos de bacilo ativo.

Na rede social da qual eu participava, as críticas ao novo protocolo traziam à discussão fortes convicções morais. A mudança proposta de protocolo era chamada de "absurda", "revoltante", "uma temeridade que chega a ser dolosa", "um crime que o ministério da saúde [estava] querendo implantar!!!" Os pronunciamentos levavam a crer que a maioria dos membros desse fórum tinha envolvimento direto no cuidado de pessoas afetadas e "conhecer a doença" não era, para eles, algo que pudesse ser traduzido em números. Dizia respeito, antes, à apreensão direta, sensorial da condição dos pacientes:

Os casos que temos visto é entristecedor!!!! Tenham certeza! Eu não conseguiria olhar para esses pacientes e tratá-los com o esquema [unificado proposto] e depois colocar minha cabeça no travesseiro e dormir!!!!

[...] não sou nenhuma autoridade, sou somente uma clínica que atende os pacientes portadores de hanseníase, em reação ou com sequela. Tenho uma coleção de recidivas de uns 70 casos!!! Não consigo entender esse tal [de regime unificado] que trata [os casos agudos com menos doses]!!! Logo o grupo que mantem o foco ativo.

Nessas conversas, os especialistas do outro lado do debate (que advogavam o encurtamento do regime de tratamento) eram descritos como profissionais que "não conhecem a realidade", que fazem uma "ciência por vaidade": "Ou se conhece a doença e se posiciona contra [o tratamento unificado], ou se vagueia na areia movediça que permeia ministérios, indicações, cargos, políticas públicas, portarias... burocracia enfim".

Ao comparar os argumentos apresentados pelos defensores e opositores da nova proposta, fica clara a rixa epistemológica entre, por um lado, a lógica quantitativa dos ensaios randomizados, legitimada pela repetibilidade e previsibilidade das evidências, e, por outro, a medicina clínica, indissociável da lógica indiciária que informa o projeto terapêutico (Camargo, 2013, p. 192) ${ }^{17}$. A diferença entre as duas abordagens vem acompanhada de uma diferença tácita de prioridades práticas: por um lado, o bem-estar da população (i.e., conter os riscos da endemia, equilibrando custo e efetividade); por outro lado, a cura e os cuidados de pacientes afetados. À medida que surgem conflitos em torno de políticas de intervenção, não é surpreendente constatar acusações mútuas: que o raciocínio do coletivo "estrangeiro" é fantasioso, suas explicações inadequadas, seus conceitos fantasiosos, suas prioridades triviais, e seus fatos "invenções livres" que devem ser ignoradas (Fleck, 2005, p. 189).

Mas, além dessa rixa, cabe notar como o conflito em torno do novo protocolo tem contribuído para a estabilização do segundo coletivo de pensamento, através da consolidação de um grupo social organizado. Trata-se de um grupo mais afeto à prática clínica do que à pesquisa laboratorial, que reivindica suas próprias tec-
17 Entre as muitas menções ao debate médico estruturado a partir dessa oposição epistemológica, ver Fassin (2007), CRUZ (2016), Desrosières (1993) 
nologias, linguagens e valores. Essa observação nos leva de volta à pergunta com a qual abrimos este artigo, agora com leve inflexão: qual o papel da ação coletiva organizada na determinação das evidências científicas que prevalecem na política de combate à hanseníase no Brasil e no mundo?”.

\section{Novos aliados, novas maneiras de validar os fatos}

Charles Briggs (2016), na sua análise de uma epidemia de raiva espalhada por morcegos na Amazônia venezuelana, sugere que o diagnóstico e a solução da praga tardaram em aparecer porque, entre especialistas da gestão pública, os saberes nativos foram durante longo tempo ignorados. A partir dessa situação, o autor cunha a noção de "ecologias de evidências", isto é: "[...] aparelhos amplos compostos de modos interconectados de produzir tipos distintos de evidência, dando mobilidade a alguns deles, reduzindo outros ao status de ignorância, superstição ou patologia, e tornando outros simplesmente impensáveis" (2016, p. 151).

Seguindo nesse rumo, poderíamos arriscar a hipótese de que, na controvérsia sobre o tratamento de hanseníase, estamos diante do que Briggs denomina "inequidades comunicativas", isto é, "a distribuição radicalmente desigual de acesso à produção e circulação de evidências". Ou seja, tal como sugere Vincanne Adams (2013, p. 84), antropóloga especializada em saúde global, as provas estatísticas - tão ao gosto de planejadores - podem ter pouco ou nada a ver com "o mundo intrinsecamente bagunçado de pessoas, saúde e doença”, mas têm a vantagem de produzir uma imagem de fatos científicos "robustos". Assim, o culto à medicina baseada em evidências - com seu particular viés epistêmico - continuaria a colonizar outras formas de evidência, especialmente no campo da saúde global, tornando contexto e história obsoletos e extraindo o cuidado clínico das relações sociais em que se apoiam.

À luz dessas reflexões, torna-se inteligível como, nas arenas executivas da saúde global onde se estabelecem os parâmetros para a coleta de dados e protocolos de tratamento, a experiência dos "clínicos" envolvidos diretamente com os pacientes foi durante certo tempo eclipsada pela evidência estatística. Da mesma forma, as teses e dissertações em diversas regiões do Brasil sugerindo altas taxas de recidivismo entre pacientes com hanseníase avançada, por causa de suas "insuficiências” metodológicas, não eram consideradas dignas de grande atenção.

Entretanto, uma "ecologia de evidências" não pressupõe uma hierarquia fixa de saberes. Justamente a vantagem dessa noção é que anuncia a possibilidade de arranjos e mesmo reviravoltas surpreendentes. É verdade, que, durante quinze anos, houve um avanço lento, mas seguro do novo protocolo, crescentemente legitimado pela "medicina baseada em evidências". Porém, embora endossado pela Estratégia Global de 2016 (OMS, 2016), já no Manual de orientações para monitoramento e avaliação do Plano publicado um ano depois (OMS 2017), não há nenhuma menção do novo protocolo. E, em meados de 2018, a OMS assumiu um recuo radical, recomendando no seu Guidelines (WHO, 2018), a manutenção do regime de tratamento vigente para pacientes $\mathrm{MB}$. Os autores do documento não 
ignoram os ECRs, mas reinterpretam os resultados, chegando à conclusão de que "[...] houve evidência insuficiente para recomendar uma diminuição na duração do regime atual de 3 medicamentos. Além disso, o único ECR disponível encontrou uma associação potencial entre menor duração do tratamento e aumento do risco de recidiva" (WHO Guidelines 2018, ênfase nossa) ${ }^{18}$.

\section{Que terá acontecido para provocar uma tal guinada?}

É possível que a mobilização fenomenal organizada pela rede "contra", com participação em peso de trabalhadores de saúde brasileiros, tenha finalmente surtido efeito. Porém, os especialistas do outro lado da contenda também se mobilizaram para ampliar seu já grande raio de aliados poderosos. Levantamos a hipótese de que, além do simples número e da escala de alianças, o fiel da balança nessa disputa - pelo menos no âmbito da OMS - é um novo desenvolvimento no cenário político: a importância dos "afetados" pela doença nos fóruns de debate.

Certamente, há tempo que os pacientes e seus familiares participam nos fóruns internacionais através de suas associações e de seus movimentos funcionando nos vários países. Entretanto, sugerimos que, nos últimos anos, houve uma crescente ênfase no valor da participação cidadã nas instituições de governo dentro e fora das arenas de saúde global. A antropóloga Alice Cruz (2016, p. 38), atual Relatora Especial da ONU para a eliminação da discriminação contra pessoas afetadas pela hanseníase e seus familiares, dá voz a essa tendência quando sublinha "a necessidade de incluir processos participativos nas tomadas de decisão como forma de precaver e gerir potenciais danos" causados pela hanseníase.

De fato, ao comparar as diferentes "estratégias globais" para o combate de hanseníase publicadas ao longo dos últimos vinte anos, não há como ignorar novidades no perfil dos envolvidos. Os planos de 2006 e 2010 não incluem detalhes sobre a identidade dos contribuintes, pautando, ao invés, uma autoria institucional genérica. Em 2016 (OMS, 2016), o documento traz uma página inteira sobre colaboradores subclassificados nas rubricas: "programas nacionais", "especialistas", "organizações parceiras" (entre as quais, cita-se uma associação de "afetados" na Índia) e "OMS”. Guidelines (WHO, 2018), por sua vez, inclui na página sobre colaboradores - além de médicos, professores e agentes de saúde pública de diversas partes do mundo -, pacientes e seus familiares. Traz os resultados de grupos focais de debate realizados com "afetados" em Colômbia, Gana, Índia e Nepal. Também registra no seu External Review Board a participação de "afetados" de hanseníase oriundos de Brasil, Paraguai, Índia, Gana e Nepal. Sem dúvida, o uso das mídias sociais (tais como o grupo WhatsApp citado acima) e a implementação via internet de Consultas Públicas têm dado visibilidade renovada à "voz" dos variavelmente afetados e interessados - criando uma nova (e quiçá influente) categoria de especialistas leigos.

Conforme Cruz (2016, p. 39), a introdução da "experiência incorporada" dos próprios pacientes provocaria uma "crise de credibilidade" no paradigma médico centrado quase exclusivamente na cura. Traria para o centro do palco pessoas
18 De fato, não só o tratamento de hanseníase MB foi mantido em doze meses, o cocktail para PB foi aumentado de dois para três antibióticos durante seis meses. 
com hanseníase que convivem com dor crônica e sequelas debilitantes, além de quadros reacionais tratados até hoje com drogas obsoletas com efeitos colaterais perigosos. Acrescentaríamos que, à medida que nos afastamos do saber médico, nos aproximando da perspectiva do paciente em sofrimento, a dimensão temporal se impõe, desafiando a rigidez das classificações estanques da biomedicina (Bowker; Star 1999, p. 192). Em particular, as "evidências alternativas" produzidas pela experiência incorporada colocariam em destaque vivências locais, revelando a fragilidade da própria noção de "cura".

Nesse sentido, o próprio bacilo, ao resistir contra as tentativas de transformar a hanseníase em uma "doença qualquer", diagnosticável e tratável dentro dos moldes tradicionais da saúde global (Cruz, 2016; Maricato, 2019), também está achando uma "voz" na determinação das evidências científicas que dirigem a intervenção. Diante das densas dobraduras temporais dos corpos, bacilos e tecnologias "em movimento" que vimos acima, como encaixar as manifestações da doença no sistema classificatório dos ECRs? Como usar esse tipo de "evidência" para demonstrar a eficácia de um tratamento se há, na raiz da investigação, ambiguidades profundas sobre os termos-chave envolvendo graus de severidade, cura e recidiva?

Vimos neste artigo como a infraestrutura classificatória exerce uma influência não negligenciável na rede sociotécnica acionada para o combate à hanseníase. Trata-se de termos médicos que se enquadram mal nas ambiguidades de uma "doença em andamento"; categorias numéricas que se encolhem ou se expandem conforme a duração do regime de tratamento; metas que modificam o registro de dados, mudando o rumo das estratégias de organizações nacionais e internacionais. Não há nada natural ou automático na delimitação dessas categorias; há contornos arbitrários, convencionados, que dependem de políticas pragmáticas negociadas dentro de determinadas relações de força.

A contenda em torno do novo protocolo de tratamento trouxe a oportunidade de observar essa infraestrutura em ação. Vimos nela como os "grandes números" da medicina baseada em evidências - elo por excelência entre fatos científicos e a implementação de políticas públicas, entre ciência e governo - são contestados.

Provocando uma espécie de "inversão infraestrutural", essa contestação coloca em destaque coletivos de pensamento distintos, cada qual mobilizando elementos morais, políticos e técnicos para validar suas respectivas verdades.

Para entender qual coletivo prevalece, retomamos num primeiro momento a provocação de Adams (2016) de que, desde os anos 1980, o raciocínio quantitativo (quantitative metrics) vem desbancando outras abordagens sem nunca ter dado resposta definitiva à questão de eficácia. Entretanto, ao seguir a trajetória desse debate adiante, nos lembramos das palavras de Latour (citadas acima), sobre a natureza imprevisível dos "outros meios" pelos quais as verdades se consolidam no campo da ciência. Os acontecimentos que se sucederam põem em xeque qual- 
quer visão reducionista da evolução da ciência. No âmbito da OMS, as "verdades" foram reelaboradas não necessariamente por força de novas evidências e, sim, por rearranjos no cenário político em que novos atores assumiam uma voz.

É irônico que, no Brasil, de onde surgiram lideranças contra o regime único de tratamento, as coisas tenham evoluído em outro ritmo. Malgrado uma consulta pública realizada online no fim de 2018 em que 95\% dos participantes (pacientes, familiares e profissionais de saúde) se pronunciaram firmemente contra o novo protocolo, a CONITEC (do Ministério de Saúde) nunca retirou seu endosso ao esquema terapêutico único. Tampouco adiantou críticos chamarem atenção para o recuo da OMS, sublinhando o fato de que, se teimasse na aprovação do novo protocolo, o Brasil seria "o único país no mundo" a implantar o regime único de tratamento (SBH 2018). Apesar de tudo, à medida que a poeira baixava, tornou-se evidente que não existia nenhuma política institucional para efetivamente implementar a mudança de esquema terapêutico ${ }^{19}$.

A trajetória inesperada na OMS quanto à recomendação de um novo protocolo de tratamento para hanseníase, assim como a discrepância entre o Brasil e a OMS, mostram a que ponto os fatos científicos acionados, longe de serem universais, são negociados em diferentes instâncias. A validação das "evidências" e as conclusões que decorrem delas dependem das infraestruturas nas quais são inseridas, incluindo categorias ambíguas e tecnologias nem sempre consensuais. As decisões são feitas no embate entre atores enredados em coletivos de pensamento cuja influência varia conforme a arena de engajamento - local, nacional ou global. Mudanças nessa rede sociotécnica podem provocar uma remexida na ecologia de saberes que, filtrada por políticas institucionais específicas, trará consequências concretas à vida de milhares de afetados. Em suma, a trajetória nem sempre previsível dessa relação entre ciência e governo põe em relevo, para além dos aspectos técnicos, os elementos políticos, dando relevância renovada à noção de "participação".
19 A terceira edição do Guia de Vigilância em Saúde lançada no início de 2019 (Brasil, 2019) manteve o protocolo antigo. E a nova Estratégia Nacional para o Enfrentamento da Hanseníase, 2019 - 2022, ao não entrar em detalhes sobre o regime recomendado de tratamento, simplesmente evita a questão. 
Claudia Fonseca

\section{Referências}

ADAMS, Vincanne. Evidence-based global public health: subject, profits, erasures. In: BIEHL, João; PETRYNA, Adriana (Orgs.). When people come first. Princeton: Princeton University Press, 2013.

ADAMS, Vincanne. What is critical global health? Medicine, Anthropology, Theory - MAT, v. 3, n. 2, p. 186-197, 2016.

BOWKER, Geoffrey; STAR, Susan L. Sorting things out: classification and its consequences. Cambridge, MA: MIT Press, 1999.

BRABER, Kommer. An evaluation of GAEL, the Global Alliance for the Elimination of Leprosy. Leprosy Review, v. 75, p. 208-213, 2004.

BRASIL. Coordenação-Geral de Desenvolvimento da Epidemiologia em Serviços. Guia de Vigilância em Saúde. 3. ed. Brasília: SVS/Ministério da Saúde, 2019.

BRIGGS, Charles. Ecologies of evidence in a mysterious epidemic. Medicine, Anthropology, Theory - MAT, v. 3, n. 2, p. 149-162, 2016.

BRUNO, Isabelle; DIDIER, Emmanuel. Benchmarking: L'État sous pression statistique. Paris: Zones, 2013.

CAMARGO, Kenneth. O paradigma clínico-epidemiológico ou biomédico. Revista Brasileira de História da Ciência, v. 6, n. 2, p. 183-195, 2013.

CARR, E. Summerson; LEMPERT, Michael (Orgs.). Scale: Discourse and Dimensions of Social Life. Oakland: University of California Press, 2016.

CARRARA, Sérgio. Tributo a Vênus: a luta contra a sífilis no Brasil, da passagem do século aos anos 40. Rio de Janeiro: Fiocruz, 1996.

CASTRO, Rosana. Precariedades oportunas, terapias insulares: economias políticas da doença e da saúde na experimentação farmacêutica. Tese (Doutorado em Antropologia Social) - Universidade de Brasília, Brasília, 2018.

CRUZ, Alice. Uma cura controversa: a promessa biomédica para a hanseníase em Portugal e no Brasil. Physis Revista de Saúde Coletiva, v. 26, n. 1, p. 25-44, 2016.

DESROSIÈRES, Alain. La politique des grands nombres. Paris: La Découverte, 1993.

DUARTE, Larissa Costa. "A maior taxa de mutação já reportada": uma reflexão sobre materialidades, produção de conhecimento, e HIV/AIDs". In: FONSECA, Claudia; MARICATO, Glaucia; DUARTE, Larissa C.; BESEN, Lucas (Orgs.). Ciência, Medicina e Perícia nas Tecnologias de Governo. Porto Alegre, CEGOV, 2017. p. 15-36.

FASSIN, Didier. When bodies remember: experiences and politics of AIDS in South Africa. Berkeley: University of California Press, 2007.

FLECK, Ludwik. Genèse et développement d'un fait scientifique. Paris: Editions Les Belles Lettres, 2005.

FONSECA, Claudia. Lá onde, cara pálida? Pensando as glórias e os limites do campo etnográfico. Mundaú, n. 2, p. 96-118, 2017.

GONÇALVES, Aguinaldo; MANTELLINI, Glauca Gonçalves; PADOVANI, Carlos Roberto. $O$ paradigma dualista da hanseníase, controle ou eliminação: o período crítico de 2000 a 2005. Hansenologia Internationalis, v. 36, n. 2, p. 17-23, 2011.

GUPTA, Akhil. Red Tape: Bureaucracy, structural violence, and poverty in India. Durham: Duke University Press, 2012.

HACKING, Ian. Taming of chance. Cambridge: Cambridge University Press, 1990. 
Claudia Fonseca

JI, Baohong. Comments on the Report entitled "Independent Evaluation of the Global Alliance for the Elimination of Leprosy”. Leprosy Review, n. 75, p. 217-220, 2005.

JI, Baohong; SAUNDERSON, Paul. Uniform MDT (U-MDT) regimen for all leprosy patientsanother example of wishful thinking. Leprosy Review, v. 74, n. 1, p. 2-6, 2003.

LATOUR, Bruno. Give me a laboratory and I will raise the world. In: KNORR-CETINA, Karin D.; MULKAY, Michael (Orgs.). Science observed: perspectives on the social study of science. London: Sage, 1983. p. 141-170.

LATOUR, Bruno. Ciência em ação: como seguir cientistas e engenheiros sociedade afora. São Paulo: Editora UNESP, 2000.

LATOUR, Bruno. Reassembling the social: an introduction to actor-network-theory. Oxford: Oxford University Press, 2005.

LOCKWOOD, Diana. Commentary: Leprosy and poverty. International Journal of Epidemiology, n. 33, p. 269-270, 2004.

LOCKWOOD, Diana; SHETTY, Vanaja; PENNA, Gerson O. Hazards of setting targets to eliminate disease: lessons from the leprosy elimination campaign. BMJ - British Medical Journal, n. 348, p. 15-17, 15 fev. 2014.

MALATHI, Munisamy; THAPPA, Devinder. Fixed-duration therapy in leprosy: limitations and opportunities. Indian Journal of Dermatology, v. 58, n. 2, p. 93-100, 2013.

MARICATO, Glaucia. Histórias sem fim: sobre dobras e políticas ontológicas de um mundo sem hanseníase. Tese (Doutorado em Antropologia Social) - Universidade Federal do Rio Grande do Sul, Porto Alegre, 2019.

MERRY, Sally Engle. Measuring the World: Indicators, human rights, and global governance. Current Anthropology, 52, sup. 3, p. 583-595, 2011.

OMS - Organização Mundial de Saúde. Estratégia Mundial de Eliminação da Lepra 20162020: acelerar a ação para um mundo sem lepra. Nova Deli: SEARO, 2016.

OMS - Organização Mundial de Saúde. Estratégia Global para Hanseníase, 2016-2020: monitoramento e avaliação. Nova Deli: SEARO, 2017.

PENNA, Gerson Oliveira; TEIXEIRA, Maria Glória; COSTA, Maria da Conceição Nascimento et al. Uniform multidrug therapy for leprosy patients in Brazil (U-MDT/CT-BR): results of an open label, randomized and controlled clinical trial, among multibacillary patients. PLOS, Neglected Tropical Disease, v. 11, n. 7, p. 1-19, 2017.

PENNA, Gerson Oliveira; PENNA, Maria Lúcia Fernandes; BARRETO, Maria Lúcia Lima et al. Nota relativa às evidências científicas quanto à utilização de um esquema uniforme e de curta duração no tratamento de hanseníase na APS. 24 abr. 2018. Disponível em: https://www.abrasco.org.br/site/outras-noticias/opiniao/nota-relativa-as-evidencias-cientificas-quando-utilizacao-de-um-esquema-uniforme-e-de-curta-duracao-no-tratamento-de-hanseniase-na-aps/34062/. Acesso em: 19 out. 2019.

PETRYNA, Adriana. When experiments travel: clinical trials and the global search for human subjects. Princeton: Princeton University Press, 2009.

RAO, P. Narasimha; DOGRA, Sunil; SUNEETHA, Sujai. Global leprosy program: does it need uniform-multi-drug therapy now? Indian Dermatology Online Journal, v. 6, n. 6 , p. 425-427, 2013.

SALGADO, Claudio Guedes; BARRETO, Josafá Gonçalves; SILVA, Moisés Batista da; FRADE, Marco Andrey Cipriani; SPENCER, John Stewart. What do we actually know about leprosy worldwide? Lancet, v. 16, n. 7, p. 778, 2016. 
Claudia Fonseca

SALGADO, Claudio Guedes; BARRETO, Josafá Gonçalves; SILVA, Moisés Batista da et al. Are leprosy case numbers reliable? Lancet, n. 18, p. 135-136, 2018.

SHORE, Chris; WRIGHT, Susan. Policy: a new field of anthropology. In: SHORE, Cris; WRIGHT, Susan (Eds.). Anthropology of Policy: critical perspectives on governance and power. London: Routledge, 1997.

SHORE, Cris; WRIGHT, Susan. Governing by numbers: audit culture, rankings and the new world order. Social Anthropology, v. 23, n. 1, p. 22-18, 2015.

SMITH, William Cairns S.; BRAKEL, Wim H. van; RICHARDUS, Jan Hendrix. The missing millions: a threat to the elimination of leprosy. PLoS Neglected Tropical Diseases, v. 9, n. 4, e0003658. Disponível em: https://doi.org/10.1371/journal.pntd.0003658. Acesso em: 19 out. 2019.

SBH - Sociedade Brasileira de Hansenologia. Posição da SBH em relação à implantação do MDT-U no Brasil: relatório apresentado à $73^{a}$ Reunião da CONITEC, dez. 2018. Disponível em: http://www.sbhansenologia.org.br/upload/files/Explana___o_oral_e_documenta o_apresentada_pela_SBH_na_CONITEC_sobre_o_ MDT-U____\%281\%29.pdf. Acesso em: 19 out. 2019.

STEFANI, Franceli. Entre o preconceito e a doença. Correio do Povo, Porto Alegre, p. 10, 2018.

TALHARI, Sinésio; GROSSI, Maria Aparecida de Faria; OLIVEIRA, Maria Leide W. D. R. de et al. Hansen's disease: a vanishing disease? Memórias do Instituto Oswaldo Cruz, n. 197, sup. 1, p. 13-16, 2012.

TRINDADE, Maria Angela Bianconcini; VARELLA, Tatiana Cristina Nogueira; CISNEROS, Claudia Gertrudis Cardoza et al. Delayed diagnosis of multibacillary leprosy: a report of eight cases. Brazilian Journal of Infectious Diseases, v. 13, n. 2, p. 155-157, 2009.

WHO - World Health Organization. The final push strategy to eliminate leprosy as a public health problem. Genebra: WHO, 2003.

WHO - World Health Organization. Guidelines for the diagnosis treatment and prevention of leprosy: executive summary. Genebra: WHO, 2018. 